reduce health care costs to the chronically ill and the handicapped; the solution is to stream such patients through the triage exit. The contributors to Bastian's collection, by contrast, are anxious that 'under the cloak of progressive "social technique" ethics may have 'crossed into the territory of inhumanity'. This dreaded outcome is the core of the contributors' moral concern.

Singer and his German colleagues say this response is emotional and greatly exaggerated. It stems, they say, from persons who still seek a reconciliation with the Nazi past, and who in consequence carry a burden of guilt. This may well be. All authors write in the shadow of this past, and two essays (Dörner and Rost) argue for its direct contemporary relevance. The argument is that the Third Reich did not originate the rationale for euthanasia, but took it over whole from the advanced thinking of the Weimar republic. To the contemporary confidence in responsible euthanasia, they say that the economic and social imperatives driving toward this solution of social problems assures that it will be abused.

What then is the remedy? At all costs to abstain from triage in medical service seems to be the alternative proposed. However, if the contributors' sketch of the economic and social imperatives driving euthanasia are accurate, abstention is not practicable, however one may assess the social risks or view the ethics of euthanasia. In that case, euthanasia would join the growing queue of essentially contested issues intractable to the usual legal and institutional techniques of conflict resolution. Perhaps a solution may be found through future study of untried options available for assorting peacefully the sharp value conflicts of pluralist societies.

HIRAM CATON, The Bonhoeffer Institute, Brisbane, Australia.

\section{Who Lives? \\ Who Dies? Ethical Criteria in Patient Selection}

John F Kilner, 358 pages, New Haven and London, 1990, Yale University

Press, £27.50.

The author is Professor of Social and
Medical Ethics at the University of Kentucky. He takes it as 'given' that it is not possible to make the benefit of dialysis and organ transplant available to all. He has identified 16 criteria from the literature which might help medical directors decide which patients to choose for treatment. He obtained over 400 replies to a questionnaire sent to directors of dialysis and transplant services in the USA (just over 40 per cent of the directors listed), asking which criteria they thought important and which they would be prepared to consider. In order to attempt some cross-cultural comparison he also interviewed 132 healers in Kenya, obtained stories from them and answers to 24 questions.

The criteria which are discussed in successive chapters are grouped under the headings: 1) Social value, (favoured group, social value, resources required, special responsibility); 2) Socio-medical criteria, (age, psychological ability, supportive environment); 3) Medical criteria, (medical benefit, length of benefit, quality of benefit); and 4) Personal criteria, (willingness, ability to pay, random selection).

Each chapter has the same format, dealing with justification, weakness of the criterion, possible common ground, and ending with an illustrative case. Finally the author examines whether it makes any difference if the proposed treatment is at an experimental stage. In the last chapter the findings are summarised, showing which criteria are most readily acceptable and which are least supported. Arguments for and against the selection criteria are characterised as either productivity or person orientated. How the weights of the arguments are to be compared is left unanswered but a drift towards utilitarian thinking in medicine is recognised. Only at the very end does the author address fundamental ethical issues such as responsibility, humanness and value of life.

Though the book makes interesting reading it has left this reviewer dissatisfied in a number of respects. First, though there is merit in consistency of presentation the result is that the book is repetitive and and unnecessarily lengthy. Second, there are 56 pages of 'notes' which is in keeping with philosophical works. However, very few of these notes amount to anything other than a list of the names to be found later in 57 pages of references. Only the notes relating to the last chapter advance the argument in any way. Third, it is disappointing that only the decisions of medical directors are considered. The views of others concerned are barely touched on. Patients themselves, relatives or members of the society who should decide about resources are hardly considered. Lastly, though the author applies a philosophical approach to the analysis of data there is little to suggest that either respondents or the patients about whom decisions were to be made had in any way become conscious of the underlying ethical issues.

As is recommended by the publishers, this book should be available to health care practitioners and to policy-makers. It would encourage them to make reasons for their decisions explicit. The introduction, the first two chapters and the last 25 pages will perhaps be all that is required for most readers, though some may wish to dip into selected chapters to consult the full range of the rationale for the final recommendations.

ANNIE T ALTSCHUL, Emeritus Professor of Nursing Studies, 24 Bruntsfield Gardens, Edinburgh.

\section{A Protestant Legacy}

Rory Williams, 371 pages, Oxford, 1990 , Clarendon Press, $£ 40.00$ hc.

A Protestant Legacy - so called by Rory Williams as a gesture towards the tangle of religious and economic issues which colour Aberdonians' attitudes to illness and death. A capitalist ethic of the value of work to the individual, linked with the Calvinist belief of misfortune as the consequence of sin, have produced in the elderly a strong belief in health as something individuals can by their own efforts achieve and that illness is something to fight against.

This book investigates the themes and dilemmas which arise when elderly Aberdonians express their attitudes to health, illness, age, dying, bereavement and their doctors. It correlates, debates and resolves those views and explains them with references to their formative influences, namely work, wealth, religion and moral or peer persuasion.

The book is predominantly supported by evidence collected by personal interview by the author of 70 Aberdonians selected from two parts of the city - one the prosperous West End and the other a council estate. Additional authenticity is obtained by reference to a random sample survey of 119 elderly Aberdonians conducted at 